Journal of Clinical Investigatıon

Vol. 41, No. 2, 1962

\title{
STUDIES ON THE ABSORPTION BY GUINEA PIG INTESTINE OF CYANOCOBALAMIN INCUBATED WITH INTRINSIC FACTOR *
}

\author{
By BERNARD A. COOPER, $\dagger$ WILLIAM PARANCHYCH AND \\ LOUIS LOWENSTEIN \\ (From the Haematology Service, Department of Medicine, Royal Victoria Hospital, McGill \\ University Clinic, and the McGill-Montreal General Hospital Research Institute, \\ Montreal, Canada)
}

(Submitted for publication July 20, 1961 ; accepted October 12, 1961)

The absorption of cyanocobalamin from the gastrointestinal tract requires the mediation of the gastric intrinsic factor (1). Although recent studies suggest that the cobamide coenzymes may be the naturally occurring form of vitamin $B_{12}$ (2), these coenzymes also require intrinsic factor for absorption from the gastrointestinal tract $(3,4)$.

The demonstration by Wilson and Strauss (5) that everted sacs of guinea pig intestine in vitro take up cyanocobalamin in the presence of human gastric juice, has provided a tool for studying the action of human intrinsic factor in vitro. We have utilized this system to study the absorption of cyanocobalamin from the gastrointestinal tract, in conjunction with studies of cyanocobalamin transport into normal and malignant cells (6).

Previous studies with perfused isolated rat intestinal loops in vivo have indicated that the absorption of cyanocobalamin is not affected by metabolic poisons (7). The difficulties associated with studies with metabolic inhibitors in vivo have prompted us to repeat these studies in the isolated sac system.

Herbert (8) has demonstrated that calcium ions are required for the uptake of hog intrinsic factor by rat intestine segments at $4^{\circ} \mathrm{C}$ in vitro, and that most of this radioactivity could be removed by subsequent rinsing with ethylenediamine tetraacetate (EDTA). This calcium dependence of intrinsic factor has been observed in vivo in the rat $(7,9)$ and in man $(10)$. Although calcium-binding materials interfere with the in-

\footnotetext{
* Supported by Grants MA-802 and MA-1016, Medical Research Council of Canada, and U. S. Public Health Service Grant C-3596.

$\dagger$ Medical Research Associate, Medical Research Council of Canada.
}

testinal absorption of a number of substances (11), the observation that a portion of the cyanocobalamin taken up in the presence of normal human gastric juice (NHGJ) by the perfused isolated rat intestine loop in vivo is removed by rinsing with EDTA, but not with saline (7), further emphasizes the probable role of bivalent cations in the physiology of absorption of vitamin $\mathrm{B}_{12}$. Because of these observations we have carried out further studies on the cationic requirements for vitamin $B_{12}$ absorption.

\section{MATERIALS AND METHODS}

Cyanocobalamin labeled with $\mathrm{Co}^{68}$ or $\mathrm{Co}^{57} 1$ (referred to as $\mathrm{Co}^{58} \mathrm{~B}_{12}$ or $\mathrm{Co}^{57} \mathrm{~B}_{12}$ ) was adjusted to a specific activity of 2 to $3 \mu \mathrm{c}$ per $\mu \mathrm{g}$ with nonradioactive cyanocobalamin. ${ }^{2}$ The cyanocobalamin solutions then were diluted with water to a concentration of $46 \mathrm{~m} \mu \mathrm{g}$ per $\mathrm{ml}$, and stored at $-20^{\circ} \mathrm{C}$ in small aliquots until used. With each experiment a standard was counted, so that the radioactivity values could be converted to millimicrograms of cyanocobalamin.

Normal human gastric juice was prepared as described previously (7) and stored at $-20^{\circ} \mathrm{C}$ in small aliquots. Rat gastric juice (RGJ) and guinea pig gastric juice (GPGJ) were collected from fasted animals by the method of Shea (12), as described previously (7).

Male guinea pigs weighing 250 to $350 \mathrm{~g}$ were killed by decapitation; the lowest $80 \mathrm{~cm}$ of small intestine was removed, and 8 everted sacs of intestine were prepared as follows: The segments were turned inside out with the aid of a plastic probe, and rinsed free of luminal material with cold 0.9 per cent saline. Each segment was made into a tied intestinal sac as described by Wilson and Wiseman (13). These sacs were numbered $1-8$, beginning with the segment adjacent to the cecum. They were injected with $0.7 \mathrm{ml}$ of medium and then placed in 25- $\mathrm{ml}$ Erlenmeyer flasks containing $5.0 \mathrm{ml}$ of incubation solution. The incubation solutions contained $\mathrm{Co}^{58} \mathrm{~B}_{12}$,

1 Obtained from Merck \& Co., Canada, Ltd.

2 Generously supplied as "standard cyanocobalamin" by Mr. I. Lesk, Merck \& Co., Canada, Ltd. 
and were adjusted so that the final ionic concentrations were those of a modified Krebs-Ringer phosphate glucose medium with the following composition, in milliequivalents per liter: $\mathrm{Na} 143, \mathrm{~K} 6, \mathrm{Mg} 0.65, \mathrm{Ca} 0.47, \mathrm{Cl}$ $150, \mathrm{PO}_{4} 3.1$; and glucose $4.7 \mathrm{mM}$. Flasks were incubated for 60 minutes in a Dubnoff metabolic shaking incubator in an atmosphere of 100 per cent oxygen at $37^{\circ} \mathrm{C}$.

It has been reported previously (7) that, when radioactive cyanocobalamin bound to NHGJ is taken up by perfused intestinal loops of rats, a portion of the radioactivity taken up, which is not removed by saline rinsing, can be removed by rinsing with EDTA. We have defined the radioactive cyanocobalamin taken up by the intestinal sacs and not removed by saline rinsing as the $\mathrm{S}$ fraction, the radioactive cyanocobalamin not removed by EDTA as the $\mathrm{E}$ fraction, and the value obtained upon subtracting the $\mathrm{E}$ from the $\mathrm{S}$ as the $\mathrm{S}-\mathrm{E}$ fraction. Thus, the cyanocobalamin taken up by the intestine was differentiated into three fractions, which were defined as follows: $S$, the value obtained after rinsing the intestine with saline; $E$, the value obtained after rinsing the intestine with EDTA; and S-E, the difference between S and $E$ (i.e., the cyanocobalamin which was washed from the intestine by rinsing with EDTA but not by rinsing with saline). In most of the studies to be described, the uptake of cyanocobalamin into each of these fractions was determined.

To study the uptake of $\mathrm{Co}^{58} \mathrm{~B}_{12}$ into the two fractions, sacs were incubated in pairs, and rinsed for 40 minutes at $4^{\circ} \mathrm{C}$ at the conclusion of the incubation period. One of each pair was rinsed with a saline rinse solution ( $\mathrm{Na}$ $155 \mathrm{mEq}$ per $\mathrm{L}, \mathrm{Cl} 137 \mathrm{mEq}$ per $\mathrm{L}, \mathrm{PO}_{4} 5 \mathrm{mEq}$ per L; $\mathrm{pH}$ 7.4) while the other was rinsed with an EDTA rinse solution ( $\mathrm{Na} 155 \mathrm{mEq}$ per $\mathrm{L}$, ethylenediamine tetraacetate $45 \mathrm{mEq}$ per $\mathrm{L} ; \mathrm{pH} 7.4$ ).

After rinsing, the sacs were blotted dry, emptied of their contents, and the sutured ends discarded; the remainder of each sac was measured, placed in a test tube, and the radioactivity determined in a well-type scintillation counter. The uptake was expressed as millimicrograms of cyanocobalamin taken up per $10 \mathrm{~cm}$ of intestine.

In order to determine if more of the cyanocobalamin taken up by the intestinal sacs could be removed by repeated rinsing, sacs were incubated in a medium containing $\mathrm{Co}^{58} \mathrm{~B}_{12}$ and NHGJ. After incubation, the sacs were rinsed with $10 \mathrm{ml}$ of the saline or EDTA rinsing solution for $20,40,60$, or 80 minutes. After each 20 minutes of rinsing, the sacs were transferred to flasks containing fresh rinsing solution. After 40 minutes of rinsing, little additional radioactivity was washed from the intestinal sacs by either the saline or EDTA rinse, and the $\mathrm{S}-\mathrm{E}$ value remained constant. For this reason, all rinsing in subsequent experiments was carried out for 40 minutes.

Digestion of the intestinal sacs in concentrated sulfuric acid before counting gave results no different from those obtained when the intestinal sacs were placed in a test tube and counted directly. For this reason, all radioactive counting was carried out on undigested in- testinal segments. Equilibrium dialysis was carried out as described previously (7).

\section{OBSERVATIONS}

In order to determine whether $\mathrm{Co}^{58} \mathrm{~B}_{12}$ bound to intrinsic factor could be absorbed by intact guinea pigs, $9.2 \mathrm{~m} \mu \mathrm{g}$ of $\mathrm{Co}^{58} \mathrm{~B}_{12}$ mixed with 0.3 $\mathrm{ml}$ of NHGJ in a total volume of $1.0 \mathrm{ml}$ was administered by stomach tube to guinea pigs anesthetized previously with pentobarbital. After 5 hours the animals were killed by decapitation and the radioactivity in the liver and kidneys was measured. This was compared with the radioactivity in the liver and kidneys of guinea pigs tube-fed $\mathrm{Co}^{58} \mathrm{~B}_{12}$ mixed with 0.9 per cent saline.

$\mathrm{Co}^{58} \mathrm{~B}_{12}$ administered with NHGJ was absorbed at least as well as was the $\mathrm{Co}^{58} \mathrm{~B}_{12}$ administered with saline. The $\mathrm{Co}^{58} \mathrm{~B}_{12}$ found in the liver and kidneys of five animals receiving $\mathrm{Co}^{58} \mathrm{~B}_{12}$ + saline was $0.75 \pm 0.24 \mathrm{~m} \mu \mathrm{g}$ (mean \pm standard deviation), whereas the $\mathrm{Co}^{58} \mathrm{~B}_{12}$ in the liver and kidneys of six animals receiving $\mathrm{Co}^{58} \mathrm{~B}_{12}+\mathrm{NHGJ}$ was $0.98 \pm 0.37 \mathrm{~m} \mu \mathrm{g}$. The liver and kidneys of two animals tube-fed $\mathrm{Co}^{58} \mathrm{~B}_{12}+$ NHGJ 2.5 hours before they were sacrificed contained only 0.05 $\mathrm{m} \mu \mathrm{g} \mathrm{Co}{ }^{58} \mathrm{~B}_{12}$. Thus, the majority of the absorbed $\mathrm{Co}^{58} \mathrm{~B}_{12}$ appeared in the liver and kidneys between 2.5 and 5 hours after tube feeding. This delayed absorption of cyanocobalamin from the intestine is similar to the pattern of absorption reported in the rat (14) and in man $(15,16)$.

Correction for biologic variation. When the uptake of $\mathrm{Co}^{58} \mathrm{~B}_{12}$ mixed with NHGJ was measured, variations in uptake were noted among intestinal sacs obtained from different animals, and among sacs obtained from a single animal. As shown in Table $I$, the variation between the amount of $\mathrm{Co}^{58} \mathrm{~B}_{12}$ taken up by different sacs derived from each animal was considerably smaller than the variation between sacs of the same number obtained from different animals. In order to correct for this biologic variation, so that the uptake under different conditions could be compared, all experiments were designed as follows. The number of different experimental conditions tested in each experiment was restricted to the number of sacs which could be obtained from one animal (eight). As described previously, each sac was numbered, so that all sacs of the same number were prepared from intestinal segments 
TABLE I

Comparison of uptake by intestinal segments of $\mathrm{Co}^{58} \mathrm{~B}_{12}$ incubated with $\mathrm{NHGJ}$ *

\begin{tabular}{|c|c|c|c|c|c|c|}
\hline \multicolumn{7}{|c|}{ Uptake ( $\mathrm{m} \mu \mathrm{g} / 10 \mathrm{~cm}$ intestine) } \\
\hline \multirow{2}{*}{$\begin{array}{c}\text { Segment } \\
\text { no. }\end{array}$} & \multicolumn{4}{|c|}{ Animal no. } & \multirow[b]{2}{*}{ Mean } & \multirow{2}{*}{$\begin{array}{c}\text { Standard } \\
\text { error }\end{array}$} \\
\hline & 1 & 2 & 3 & 4 & & \\
\hline 1 & 0.47 & 0.73 & 1.58 & 1.95 & 1.18 & 0.21 \\
\hline 2 & 0.75 & 0.78 & 1.66 & 1.42 & 1.15 & 0.18 \\
\hline 3 & 0.79 & 0.90 & 1.44 & 1.76 & 1.22 & 0.20 \\
\hline 4 & 0.51 & 1.09 & 1.65 & 2.49 & 1.43 & 0.37 \\
\hline 5 & 0.76 & 0.93 & 1.78 & 1.95 & 1.35 & 0.26 \\
\hline 6 & 0.43 & 0.96 & 1.61 & 2.07 & 1.27 & 0.31 \\
\hline 7 & 0.59 & 0.79 & 1.94 & 1.77 & 1.27 & 0.29 \\
\hline 8 & 0.34 & 0.70 & 1.38 & 2.32 & 1.18 & 0.38 \\
\hline Mean & 0.58 & 0.86 & 1.63 & 1.84 & 1.26 & \\
\hline $\begin{array}{c}\text { Standard } \\
\text { error }\end{array}$ & 0.06 & 0.04 & 0.05 & 0.12 & 0.03 & \\
\hline
\end{tabular}

* Uptake by intestinal segments from 4 animals of $\mathrm{Co}^{58} \mathrm{~B}_{12}$ incubated for 60 minutes with NHGJ. The segments were rinsed in saline rinse solution after incubation. Correction is made for the large variation between animals, and between segments obtained from 1 animal, by calculating the mean uptake of each segment for all 4 animals.

situated the same distance from the cecum. Each experiment was repeated in a sufficient number of animals so that each experimental condition could be tested in each of sacs 1-8. In order to accomplish this, each sac was obtained from a different animal.

At the conclusion of the experiment, the mean value for each experimental condition was calculated. Since this mean value was a correction for the segment-to-segment and animal-to-animal variation, it was found to be less variable than the values obtained when sacs obtained from one animal were used. In some experiments fewer experimental conditions were tested, and so this "round-robin" scheme was completed by using fewer than eight animals. In all of the experiments using everted intestinal sacs described below, results are expressed as the mean value, defined in this way.

Cyanocobalamin-binding capacity of normal human gastric juice. To determine the concentration of NHGJ which, when mixed with a standard quantity of $\mathrm{Co}^{58} \mathrm{~B}_{12}$, would produce optimal uptake of cyanocobalamin by intestinal sacs, the sacs were incubated in different concentrations of NHGJ mixed with $13.8 \mathrm{~m} \mu \mathrm{g} \mathrm{Co}^{58} \mathrm{~B}_{12}$. As more NHGJ was added, the uptake by the intestinal segments increased to a maximum and then decreased. The maximum corresponded to the binding capacity of the NHGJ for vitamin $\mathrm{B}_{12}$ when measured by equilbrium dialysis. In all subsequent experiments the concentration of NHGJ was adjusted to bind all of the cyanocobalamin in the medium.

The uptake by intestinal sacs of $\mathrm{Co}^{58} \mathrm{~B}_{12}$ incubated in a medium containing $9.2 \mathrm{~m} \mu \mathrm{g}$ of $\mathrm{Co}^{58} \mathrm{~B}_{12}$, without intrinsic factor, was 0.25 to 0.38 m $\mu \mathrm{g}$ per $10 \mathrm{~cm}$. None of this could be removed by EDTA rinsing. Thus, no S-E fraction was found when $\mathrm{Co}^{58} \mathrm{~B}_{12}$ alone was incubated with intestinal sacs.

Kinetics of uptake. The rate of uptake of $\mathrm{Co}^{58} \mathrm{~B}_{12}$ into the $\mathrm{E}$ and $\mathrm{S}-\mathrm{E}$ fractions of guinea pig intestine in vitro is illustrated in Figure 1. It is apparent that the pattern of uptake into both fractions is linear with time for 60 minutes. The curves have been fitted by the method of least squares to the points determined experimentally. Different experiments designed to investigate more completely the rate of uptake of $\mathrm{Co}^{58} \mathrm{~B}_{12}$ incubated with NHGJ have revealed that the rate of uptake is constant from 0 to 60 minutes. In these experiments $9.2 \mu \mathrm{g} \mathrm{Co}{ }^{58} \mathrm{~B}_{12}$ and $0.4 \mathrm{ml}$ NHGJ were present in each incubation vessel.

Intestinal sacs were incubated in different concentrations of a $\mathrm{Co}^{58} \mathrm{~B}_{12}-\mathrm{NHGJ}$ mixture. As the concentration of the $\mathrm{B}_{12}$-NHGJ mixture was increased, the uptake per $10 \mathrm{~cm}$ of intestine increased in an exponential fashion and approached a maximum, as shown in Figure 2. The pattern

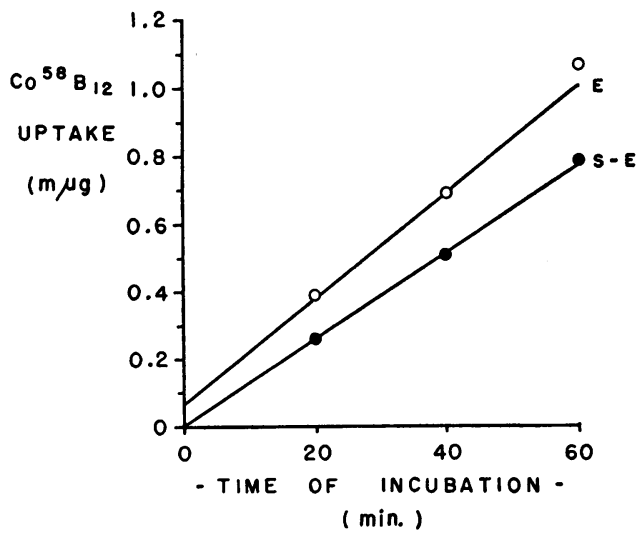

Fig. 1. Rate of uptake by guinea PIg intestine of $\mathrm{Co}^{\mathrm{s}} \mathrm{B}_{12}$ INCUBATED WITH NORMAL HUMAN GASTRIC JUICE. Intestinal sacs incubated in vitro for different periods in medium containing $9.2 \mathrm{~m} \mu \mathrm{g} \mathrm{Co}^{58} \mathrm{~B}_{12}$ and $0.4 \mathrm{ml} \mathrm{NHGJ}$. The uptake of $\mathrm{Co}^{58} \mathrm{~B}_{12}$ into the $\mathrm{E}$ and $\mathrm{S}-\mathrm{E}$ fractions is expressed as $\mathrm{m} \mu \mathrm{g} \mathrm{Co}{ }^{68} \mathrm{~B}_{12}$ per $10 \mathrm{~cm}$ of intestine. The curves were calculated by the method of least squares. 


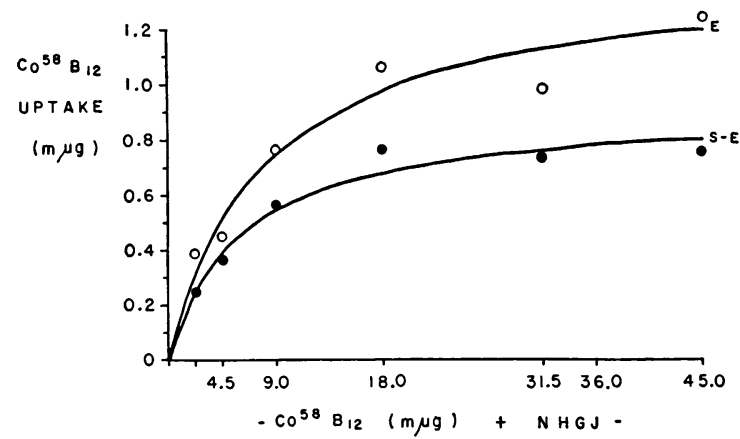

Fig. 2. EFFect of Concentration of $\mathrm{Co}^{58} \mathrm{~B}_{12}$-NHGJ MIXTURE ON UPTAKE OF $\mathrm{Co}^{38} \mathrm{~B}_{12}$ BY INTESTINAL SACS. Intestinal sacs were incubated for 60 minutes in vitro in medium containing different concentrations of $\mathrm{Co}^{58} \mathrm{~B}_{12}$ and an equivalent quantity of NHGJ. The uptake into the $\mathrm{E}$ and $\mathrm{S}-\mathrm{E}$ fractions is compared. Curves were calculated by the method of least squares. In this experiment, the mixture contained $22.5 \mathrm{~m} \mu \mathrm{g} \mathrm{Co}^{58} \mathrm{~B}_{12}$ per $\mathrm{ml}$ NHGJ.

of uptake with increasing concentration was similar for both the S-E and the $\mathrm{E}$ fractions.

Metabolic inhibitors. To study the metabolic requirements of vitamin $B_{12}$ uptake in the presence of NHGJ, intestinal sacs were incubated for 60 minutes in incubation solutions, under different conditions. The sacs were incubated: at $4^{\circ} \mathrm{C}$

TABLE II

Effect of metabolic inhibitors on uptake by guinea pig intestinal sacs of $\mathrm{Co}^{58} \mathrm{~B}_{12}$ incubated with $\mathrm{NHGJ}^{*}$

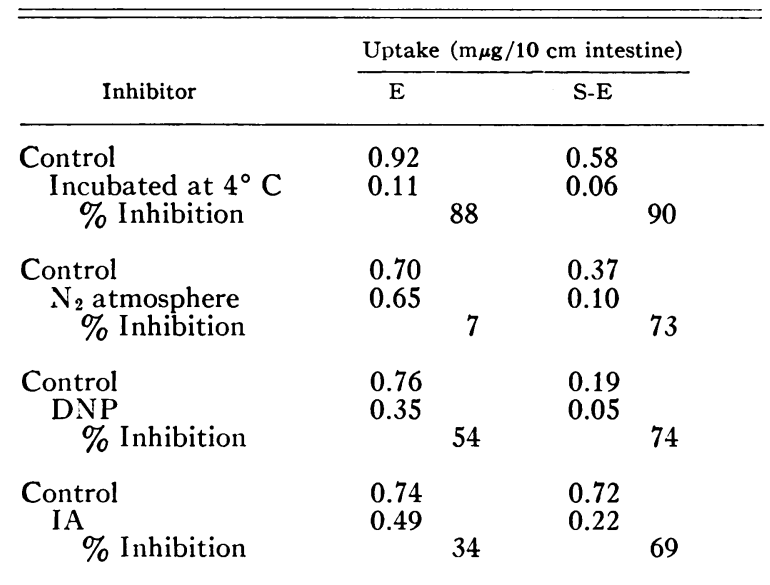

* Intestinal sacs were incubated in a medium containing $\mathrm{Co}^{58} \mathrm{~B}_{12}$ and NHGJ. The effect of incubation at $4^{\circ}$ and at $37^{\circ} \mathrm{C}$, in an atmosphere of nitrogen, and with $1 \mathrm{mM} 2,4-$ dinitrophenol (DNP), or $1 \mathrm{mM}$ sodium iodoacetate (IA), is compared with incubation at $37^{\circ} \mathrm{C}$ in oxygen (control). Uptake is divided into: $\mathrm{E}$, residual $\mathrm{Co}^{58} \mathrm{~B}_{12}$ after EDTA rinsing; and S-E, the quantity of $\mathrm{Co}^{58} \mathrm{~B}_{12}$ removed by rinsing with EDTA but not with saline.
TABLE III

Effect of cyanide on uptake by guinea pig intestinal sacs of $\mathrm{Co}^{58} B_{12}$ incubated with human, rat, and guinea pig gastric juice *

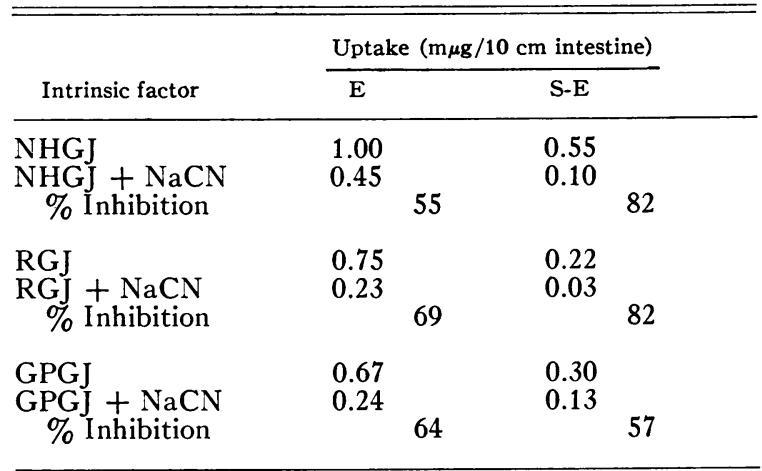

* Intestinal sacs were incubated in a medium containing $9.2 \mathrm{~m} \mu \mathrm{g} \mathrm{Co}{ }^{58} \mathrm{~B}_{12}$ and NHGJ, RGJ, and GPGJ. The effect on uptake of $\mathrm{Co}^{58} \mathrm{~B}_{12}$ of $1 \mathrm{mM}$ cyanide in the medium is compared.

in oxygen; at $37^{\circ} \mathrm{C}$ under anaerobic conditions; at $37^{\circ} \mathrm{C}$ in oxygen, in the presence of $1 \mathrm{mM} \mathrm{2,4-}$ dinitrophenol (DNP); or at $37^{\circ} \mathrm{C}$ in oxygen, in the presence of $1 \mathrm{mM}$ sodium iodoacetate (IA).

As shown in Table II, marked inhibition of $\mathrm{Co}^{58} \mathrm{~B}_{12}$ uptake was noted at $4^{\circ} \mathrm{C}$. At $37^{\circ} \mathrm{C}$, under anaerobic conditions and in the presence of $1 \mathrm{mM}$ dinitrophenol or iodoacetate, some inhibition of uptake was noted. This inhibition was more striking in the S-E fraction than in the $\mathrm{E}$ fraction. The inhibition of uptake observed during incubation under anaerobic conditions was much less marked than that observed by Strauss and Wilson (17). The explanation for this is not apparent.

As shown in Table III, $1 \mathrm{mM}$ sodium cyanide inhibited the uptake of vitamin $\mathrm{B}_{12}$ incubated with normal human gastric juice, rat gastric juice, and guinea pig gastric juice. However, whereas uptake into the $\mathrm{S}-\mathrm{E}$ fraction was more severely affected when NHGJ and RGJ were used, cyanide appeared to affect uptake into both fractions to an equal degree when GPGJ was used. Whether this represents a difference between homologous and heterologous intrinsic factor is not apparent at this time.

Cationic requirements. In order to determine the cationic requirements of vitamin $\mathrm{B}_{12}$ uptake by intestinal sacs in the presence of NHGJ, sacs were incubated in solutions containing $\mathrm{Co}^{58} \mathrm{~B}_{12}$ and NHGJ in Krebs-Ringer phosphate glucose 
TABLE IV

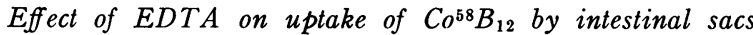
incubated in vitro with $N H G J$ *

\begin{tabular}{|c|c|c|}
\hline \multirow{2}{*}{$\begin{array}{l}\text { EDTA } \\
\text { concentration }\end{array}$} & \multicolumn{2}{|c|}{$\begin{array}{l}\text { Uptake of } \mathrm{Co}^{58} \mathrm{~B}_{12} / 10 \mathrm{~cm} \\
\text { intestine }\end{array}$} \\
\hline & $\mathrm{E}$ & S-E \\
\hline$m M$ & \multicolumn{2}{|c|}{$m \mu g$} \\
\hline 0 & 0.77 & 0.23 \\
\hline 0.045 & 0.82 & 0.31 \\
\hline 0.09 & 0.38 & 0.00 \\
\hline 0.225 & 0.28 & 0.03 \\
\hline
\end{tabular}

* Uptake into $\mathrm{E}$ and S-E fractions of sacs of guinea pig intestine incubated in vitro with NHGJ in solutions containing different concentrations of EDTA.

(KRPG), in calcium- and magnesium-deficient $\mathrm{KRPG}$, and in calcium- and magnesium-deficient KRPG containing different concentrations of EDTA. The final sodium concentration of these incubation solutions was adjusted to $155 \mathrm{mM}$. The omission of calcium and magnesium from the Ringer's solutions did not affect uptake of $\mathrm{Co}^{58} \mathrm{~B}_{12}$ incubated with NHGJ. In one experiment mean $\mathrm{E}$ and $\mathrm{S}-\mathrm{E}$ values were 1.04 and $0.68 \mathrm{~m} \mu \mathrm{g}$, respectively, when the complete KRPG was used, and 0.96 and $0.68 \mathrm{~m} \mu \mathrm{g}$, respectively, when calcium- and magnesium-deficient KRPG were used.

As shown in Table IV, the addition of small amounts of disodium EDTA abolished $\mathrm{B}_{12}$ uptake. Although "ion-free" water was used for these experiments, the water was not analyzed to determine its cationic content.

To determine the relative importance of calcium, magnesium, manganous, and ferrous ions on vitamin $B_{12}$ uptake in the presence of NHGJ, sacs were incubated in calcium- and magnesiumdeficient KRPG containing $0.18 \mathrm{mM}$ sodium EDTA, calcium EDTA, magnesium EDTA, manganous EDTA or ferrous EDTA. All solutions were adjusted to $\mathrm{pH} 7.4$.

As shown in Table $\mathrm{V}$, calcium, manganous, and ferrous ions prevented the EDTA-induced inhibition of uptake of $\mathrm{Co}^{58} \mathrm{~B}_{12}$ by the intestine, whereas magnesium ions did not. However, as shown in Table VI, when only $0.45 \mu$ mole of EDTA per vessel was added (final concentration, $0.09 \mathrm{mM}$ ), the inhibition was corrected by either calcium or magnesium. Thus, in the presence of $0.09 \mathrm{mM}$ EDTA, calcium and magnesium were equally effective in restoring $B_{12}$ uptake. When a higher concentration of EDTA was present
$(0.18 \mathrm{mM})$, only calcium and the cations tested that showed a stronger affinity for EDTA than calcium (18) (viz, manganous and ferrous ions). restored the uptake.

Transport into serosal fluid. As observed by Strauss and Wilson (17), no significant transport of $\mathrm{Co}^{58} \mathrm{~B}_{12}$ into the serosal solutions was detected at any time. When everted intestinal sacs were obtained from animals tube-fed $\mathrm{Co}^{58} \mathrm{~B}_{12}$ and NHGJ 2 hours previously, or from anesthetized animals in which $\mathrm{Co}^{58} \mathrm{~B}_{12}$ had been instilled into isolated intestine segments in vivo 1 to 2 hours previously, significant quantities of $\mathrm{Co}^{58} \mathrm{~B}_{12}$ were not found in the serosal fluid after incubation in vitro.

Relationship between $E$ and $S-E$ fractions. It has been suggested previously that vitamin $B_{12}$ taken up by the intestine may first enter the S-E fraction and then move into the $E$ fraction (7). In order to test this hypothesis, and to determine the relationship of these two fractions, the following experiment was carried out. Intestinal sacs were incubated for 40 minutes in the incubation medium containing NHGJ and $9.2 \mathrm{~m} \mu \mathrm{g}$ of $\mathrm{Co}^{58} \mathrm{~B}_{12}$. Then some of the sacs were rinsed with

TABLE V

Effect of ions on uptake, by everted intestinal sacs in vitro, of $\mathrm{Co}^{58} B_{12}$ incubated with NHGJ *

\begin{tabular}{|c|c|c|c|c|}
\hline \multirow{2}{*}{$\begin{array}{c}\text { Expt. } \\
\text { no. }\end{array}$} & \multirow{2}{*}{$\begin{array}{l}\text { Ions added to } \\
\text { incubation } \\
\text { medium }\end{array}$} & \multicolumn{3}{|c|}{$\begin{array}{l}\text { Uptake of } \mathrm{Co}^{58} \mathrm{~B}_{12} \text { by } \\
\text { intestine } \\
\text { Fractions }\end{array}$} \\
\hline & & $\mathrm{S}$ & $\mathrm{E}$ & $\overline{\mathrm{S}-\mathrm{E}}$ \\
\hline 1 & $\begin{array}{l}\text { Control } \\
\text { Na EDTA } \\
\text { Ca EDTA } \\
\text { Mg EDTA }\end{array}$ & $\begin{array}{l}m \mu g \\
1.60 \\
0.24 \\
1.48 \\
0.32\end{array}$ & $\begin{array}{l}m \mu g \\
1.02 \\
0.22 \\
1.08 \\
0.30\end{array}$ & $\begin{array}{l}m \mu g \\
0.58 \\
0.02 \\
0.40 \\
0.02\end{array}$ \\
\hline 2 & $\begin{array}{l}\text { Control } \\
\text { Na EDTA } \\
\text { Ca EDTA } \\
\text { Mn EDTA }\end{array}$ & $\begin{array}{l}1.22 \\
0.21 \\
1.34 \\
1.11\end{array}$ & $\begin{array}{l}0.84 \\
0.21 \\
0.88 \\
0.76\end{array}$ & $\begin{array}{l}0.38 \\
0.00 \\
0.46 \\
0.35\end{array}$ \\
\hline 3 & $\begin{array}{l}\text { Control } \\
\text { Na EDTA } \\
\text { Ca EDTA } \\
\text { Fe EDTA }\end{array}$ & $\begin{array}{l}1.72 \\
0.17 \\
1.76 \\
1.88\end{array}$ & $\begin{array}{l}1.17 \\
0.17 \\
1.23 \\
1.19\end{array}$ & $\begin{array}{l}0.55 \\
0.00 \\
0.53 \\
0.69\end{array}$ \\
\hline
\end{tabular}

* Mean uptake by guinea pig intestine of $\mathrm{Co}^{58} \mathrm{~B}_{12}$ incubated with NHGJ. The uptake is divided into: $S$, residual radioactivity after saline rinsing; E, after EDTA rinsing; and S-E, the difference between these. Each incubation vessel contained $9.2 \mathrm{~m} \mu \mathrm{g} \mathrm{Co}^{58} \mathrm{~B}_{12}, 0.3 \mathrm{ml}$ NHGJ, and $9.0 \mu \mathrm{M}$ of the cationic chelate in $5 \mathrm{ml}$ of $\mathrm{Ca}^{++}$- and $\mathrm{Mg}^{++}$-deficient Krebs-Ringer phosphate glucose medium. 
buffered saline and some with the EDTA rinsing solution. After saline rinsing to remove the EDTA, the sacs were reincubated in fresh solutions containing $9.2 \mathrm{~m} \mu \mathrm{g} \mathrm{Co}{ }^{57} \mathrm{~B}_{12}$ and NHGJ for an additional 20 minutes. The results of this sequential incubation are shown in Figure 3. It will be noted that after saline rinsing and reincubation in the second medium the linear uptake of cyanocobalamin with time into the $\mathrm{E}$ and $\mathrm{S}-\mathrm{E}$ fractions was unchanged. The $\mathrm{Co}^{58} \mathrm{~B}_{12}$ taken up during the first 40 minutes of incubation did not move from the $\mathrm{S}-\mathrm{E}$ to the $\mathrm{E}$ fraction during the subsequent 20 minutes of incubation, while $\mathrm{Co}^{57} \mathrm{~B}_{12}$ was being taken up. After EDTA rinsing, $\mathrm{Co}^{57} \mathrm{~B}_{12}$ was taken up into the S-E and $\mathrm{E}$ fractions at the same rate at which $\mathrm{Co}^{58}$ had been taken up previously.

This experiment shows that the S-E and $\mathrm{E}$ fractions do not represent sequential phases of uptake, that the two fractions are not in active equilibrium, and that EDTA rinsing does not damage the intestine, because the rate of uptake of vitamin $B_{12}$ after EDTA rinsing is identical with that before rinsing.

Effect of saline and EDTA rinsing on segments of intestine incubated in vivo. To determine if an S-E fraction could be demonstrated in vivo, fasted guinea pigs were tube-fed $9.2 \mathrm{~m} \mu \mathrm{g}$ of $\mathrm{Co}^{58}$ cyanocobalamin together with $0.3 \mathrm{ml}$ of NHGJ or saline. After 5 hours, the animals were decapitated, and the small intestine was removed and divided into segments $10 \mathrm{~cm}$ in length. Usually 12 segments were obtained from each animal. Alternate segments were rinsed in saline or EDTA rinsing solutions. The results are summarized in Table VII. Results are expressed as the sum of the $\mathrm{Co}^{58} \mathrm{~B}_{12}$ from all segments from

TABLE VI

Effect of calcium and magnesium on correction of the inhibition of $\mathrm{Co}^{58} \mathrm{~B}_{12}$ uptake induced by $0.09 \mathrm{mM} E D T A$ in KRPG

\begin{tabular}{|c|c|c|c|}
\hline \multirow{2}{*}{$\begin{array}{l}\text { Ions added to } \\
\text { incubation } \\
\text { medium }\end{array}$} & \multicolumn{3}{|c|}{$\begin{array}{c}\text { Uptake of } \mathrm{Co}^{58} \mathrm{~B}_{12} \text { by intestine } \\
\text { Fractions }\end{array}$} \\
\hline & $\mathrm{S}$ & $\mathrm{E}$ & S-E \\
\hline & $m \mu g$ & $m \mu g$ & $m \mu g$ \\
\hline Control & 1.73 & 1.17 & 0.56 \\
\hline $\mathrm{Na}$ EDTA & 0.17 & 0.17 & 0.00 \\
\hline Ca EDTA & 1.76 & 1.23 & 0.53 \\
\hline Mg EDTA & 1.88 & 1.19 & 0.69 \\
\hline
\end{tabular}

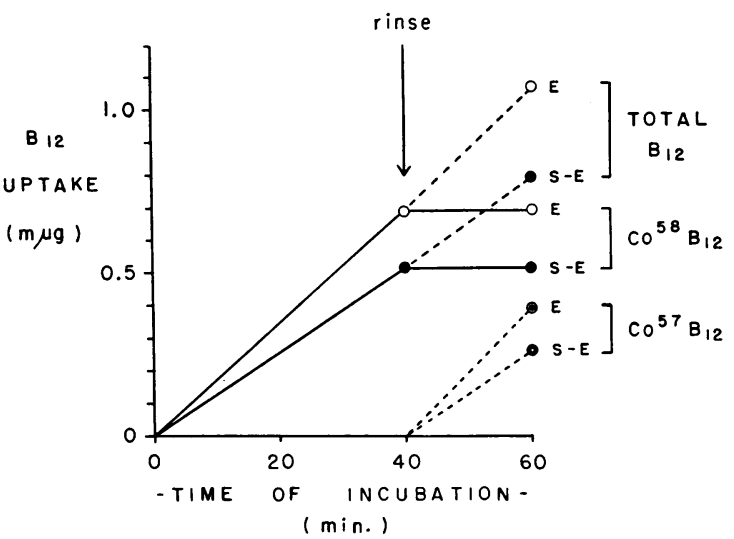

Fig. 3. Sequential incubation of intestinal sacs In $\mathrm{Co}^{58} \mathrm{~B}_{12}$ ANd NHGJ, ANd IN $\mathrm{Co}^{57} \mathrm{~B}_{12}$ ANd NHGJ. Intestinal sacs were incubated for 40 minutes in medium containing $\mathrm{Co}^{58} \mathrm{~B}_{12}$ and NHGJ. They then were rinsed with saline or EDTA rinsing solutions, and reincubated in fresh medium containing $\mathrm{Co}^{57} \mathrm{~B}_{12}$ and NHGJ. The uptake of each isotope into the $\mathrm{S}$ and $\mathrm{S}-\mathrm{E}$ fractions was compared. $E$ values are indicated by $O$, and $S-E$ values by - Solid lines indicate $\mathrm{Co}^{58} \mathrm{~B}_{12}$, and dotted lines $\mathrm{Co}^{57} \mathrm{~B}_{1:}$ taken up per $10 \mathrm{~cm}$ of intestine. In this experiment each vessel contained $9.2 \mathrm{~m} \mu \mathrm{g} \mathrm{Co}{ }^{58}-$ or $\mathrm{Co}^{57} \mathrm{~B}_{12}$ and $0.3 \mathrm{ml}$ NHGJ.

each animal, which were rinsed in saline or EDTA. It is apparent that, in all animals, the sum of the $\mathrm{Co}^{58} \mathrm{~B}_{12}$ in the segments rinsed in saline was higher than that in the segments rinsed in EDTA. Thus, even 5 hours after tube feeding, when con-

TABLE VII

Effect of saline and EDTA rinsing on $\mathrm{Co}^{58} B_{12}$ in guinea pig intestine after 5 hours of incubation in vivo*

\begin{tabular}{|c|c|c|c|c|}
\hline \multirow{2}{*}{$\underset{\text { no. }}{\text { Animal }}$} & \multirow[b]{2}{*}{ NHGJ } & \multicolumn{3}{|c|}{$\begin{array}{c}\text { Total } \mathrm{Co}^{58} \mathrm{~B}_{12} \text { uptake by intestine } \\
\text { Fractions }\end{array}$} \\
\hline & & $\mathrm{s}$ & $\mathrm{E}$ & S-E \\
\hline & & $m \mu g$ & $m \mu g$ & $m \mu g$ \\
\hline 1 & + & 1.57 & 0.92 & 0.63 \\
\hline 2 & + & 0.92 & 0.63 & 0.29 \\
\hline 3 & + & 0.61 & 0.56 & 0.05 \\
\hline Mean & + & 1.04 & 0.71 & 0.33 \\
\hline 4 & - & 0.89 & 0.73 & 0.16 \\
\hline 5 & - & 0.54 & 0.44 & 0.10 \\
\hline Mean & - & 0.72 & 0.59 & 0.13 \\
\hline
\end{tabular}

* Mean uptake into $\mathrm{S}, \mathrm{E}$, and $\mathrm{S}-\mathrm{E}$ fractions of the intestine of guinea pigs tube-fed $\mathrm{Co}^{58} \mathrm{~B}_{12}$ with and without NHGJ. Five hours after tube feeding, the intestine was divided into $10-\mathrm{cm}$ segments, and alternate segments were rinsed with saline or with EDTA rinsing solutions. (Total values are given for segments from each animal, rinsed with either saline or EDTA.) 
siderable $\mathrm{Co}^{58} \mathrm{~B}_{12}$ was present in the liver, an $\mathrm{S}-\mathrm{E}$ component was found in the intestine. This suggests that the division into $\mathrm{E}$ and $\mathrm{S}-\mathrm{E}$ fractions is not peculiar to the in vitro incubation system, and that neither fraction represents an early, transient phase of vitamin $\mathrm{B}_{12}$ absorption.

\section{DISCUSSION}

These data indicate that the intact guinea pig absorbs cyanocobalamin bound to human intrinsic factor. Previous studies $(19,20)$ have demonstrated that the cyanocobalamin molecules which are bound to intrinsic factor are absorbed in the gastrectomized rat and in man. Thus, the guinea pig appears to be capable of absorbing cyanocobalamin, using either human or guinea pig intrinsic factor.

We have demonstrated again that the cyanocobalamin taken up by intestinal sacs incubated with intrinsic factor may be separated into two fractions: one which is removed by EDTA rinsing but not by saline rinsing (S-E), and one which is not removed by EDTA rinsing $(\mathrm{E})$. The uptake of cyanocobalamin into each fraction is linear with time, and describes an exponential curve with increasing concentrations of gastric juicecyanocobalamin mixture. These fractions may be differentiated during the absorption of cyanocobalamin in vivo, whether the cyanocobalamin is bound to human intrinsic factor or is free to combine with guinea pig intrinsic factor. They could be recognized 5 hours after tube feeding of cyanocobalamin, at a time when cyanocobalamin was leaving the intestine and being deposited in the liver and kidneys.

In previous experiments with the isolated, perfused rat intestinal loop in vivo, an S-E fraction was detected when human gastric juice was used as a source of intrinsic factor, but no S-E was present when rat gastric juice was used (7). In the guinea pig intestinal preparation, an S-E fraction was present when human, rat, or guinea pig gastric juice was used.

It is tempting to speculate that the S-E fraction may be composed of cyanocobalamin loosely bound to the intestinal surface by partially competent intrinsic factor molecules, or, conversely, of cyanocobalamin and intrinsic factor molecules attached to inefficient intestinal receptors by means of bivalent cations. However, the inhibition of uptake into the S-E fraction by metabolic inhibitors would suggest that this fraction may have physiologic function. It is clear that, as cyanocobalamin is absorbed, it does not progress through one fraction into the other.

The apparent calcium dependence of uptake into both phases suggests that calcium ions may be necessary for absorption of cyanocobalamin bound to intrinsic factor. The demonstration that calcium ions may be necessary for the absorption of many substances (11) implies that calcium dependence may be a more general phenomenon than has been suggested previously (7). The failure of Abels and associates (21) to demonstrate inhibition of cyanocobalamin absorption with EDTA in vivo is of interest, and may have been due to the difficulty of chelating intestinal calcium in vivo. The calcium dependence of cyanocobalamin absorption by way of the intrinsic factor mechanism in vivo would appear to be well established (7, 9, $10,22,23$ ). The replacement of calcium by magnesium in the presence of low concentrations of EDTA $(0.09 \mathrm{mM})$ may be due to a calciumsparing effect. With higher concentrations of EDTA $(0.18 \mathrm{mM})$, only cations with greater affinity for EDTA than calcium ( $\mathrm{Mn}$ and $\mathrm{Fe}$ ) replaced calcium and allowed normal uptake of cyanocobalamin bound to human intrinsic factor.

The data available are insufficient to determine the importance of the S-E and $E$ fractions of absorbed intestinal cyanocobalamin in the physiologic absorption of cyanocobalamin from the gastrointestinal tract. However, the recognition of these fractions requires that future studies differentiate between them when the uptake of cyanocobalamin by intestinal preparations is studied.

\section{SUMMARY}

1. The intact guinea pig absorbs cyanocobalamin bound to human intrinsic factor from the gastrointestinal tract.

2. The cyanocobalamin absorbed in vivo, and taken up by intestinal sacs incubated with gastric juice in vitro, can be differentiated into two fractions: one which is removed by EDTA rinsing (S-E), and one which cannot be removed by EDTA rinsing (E).

3. Uptake into the $\mathrm{S}-\mathrm{E}$ and $\mathrm{E}$ phases in vitro is inhibited to different degrees by metabolic inhibitors. 
4. The S-E and $E$ fractions do not represent sequential phases of absorption of cyanocobalamin from the intestine.

5. The uptake of cyanocobalamin incubated with human gastric juice by intestinal sacs appears to be dependent upon the presence of calcium ions in the medium.

\section{ACKNOWLEDGMENT}

We are grateful to Professor J. H. Quastel for his advice and assistance, and to Miss Helle Puupill for technical assistance.

\section{REFERENCES}

1. Castle, W. B. Factors involved in the absorption of vitamin $\mathrm{B}_{12}$. Gastroenterology 1959, 37, 377.

2. Toohey, J. I., and Barker, H. A. Isolation of coenzyme $\mathrm{B}_{12}$ from liver. J. biol. Chem. 1961, 236, 560 .

3. Wasserman, L. R., Estren, S., Brody, E., and Herbert, $V$. Intestinal absorption of vitamin $B_{12}$ Lancet 1960, 1, 173.

4. Gräsbeck, R., and Björksten, F. Intestinal absorption of vitamin $B_{12}$ and the $B_{12}$ coenzymes. Lancet 1960, 1, 337.

5. Wilson, T. H., and Strauss, E. W. Some species differences in the intrinsic factor stimulation of $B_{12}$ uptake by small intestine in vitro. Amer. J. Physiol. 1959, 197, 926.

6. Cooper, B. A., and Paranchych, W. Selective uptake of specifically bound cobalt 58 vitamin $B_{12}$ by human and mouse tumour cells. Nature (Lond.) 1961, 191, 393.

7. Cooper, B. A., and Castle, W. B. Sequential mechanisms in the enhanced absorption of vitamin $B_{12}$ by intrinsic factor in the rat. J. clin. Invest. 1960, 39, 199.

8. Herbert, V. Mechanism of intrinsic factor action in everted sacs of rat small intestine. J. clin. Invest. 1959, 38, 102.

9. Gräsbeck, R., and Nyberg, W. Inhibition of radiovitamin $B_{12}$ absorption by ethylenediaminetetraacetate (EDTA) and its reversal by calcium ions. Scand. J. clin. Lab. Invest. 1958, 10, 448.

10. Gräsbeck, R., Kantero, I., and Siurala, M. Influence of calcium ions on vitamin $B_{12}$ absorption in steatorrhoea and pernicious anaemia. Lancet 1959, $1,234$.

11. Sognen, E. Intestinal absorption influenced by calcium-binding substances (abstract). Proc., Second Scand. Summer Meeting, Biochem., Med., Chem., Pharmacol., and Physiol., Turku, 1959, p. 67.

12. Shea, S. M. Inhibition of gastric secretion in rats by some quaternary derivatives of atropine. Brit. J. Pharmacol. 1956, 11, 171.

13. Wilson, T. H. M., and Wiseman, G. Use of sacs of everted small intestine for study of transference of substances from mucosal to serosal surface. J. Physiol. (Lond.) 1954, 123, 116.

14. Booth, C. C., Chanarin, I., Anderson, B. B., and Mollin, D. L. The site of absorption and tissue distribution of orally administered ${ }^{56}$ Co-labelled vitamin $B_{12}$ in the rat. Brit. J. Haemat. 1957, 3, 253.

15. Booth, C. C., and Mollin, D. L. Plasma, tissue and urinary radioactivity after oral administration of ${ }^{56}$ Co-labelled vitamin $B_{12}$. Brit. J. Haemat. 1956, 2, 223.

16. Doscherholmen, A., and Hagen, P. S. A dual mechanism of vitamin $B_{12}$ plasma absorption. J. clin. Invest. 1957, 36, 1551.

17. Strauss, E. W., and Wilson, T. H. Factors controlling $\mathrm{B}_{12}$ uptake by intestinal sacs in vitro. Amer. J. Physiol. 1960, 198, 103.

18. Handbook of Chemistry and Physics, 42nd ed., C. D. Hodgman, Ed. Cleveland, Chemical Rubber Publishing Co., 1960, p. 1486.

19. Bishop, R. C., Toporek, M., Nelson, N. A., and Bethell, F. H. The relationship of binding power to intrinsic factor activity (abstract). J. Lab. clin. Med. 1955, 46, 796.

20. Nieweg, H. O., Shen, S. C., and Castle, W. B. Mechanism of intrinsic factor action in the gastrectomized rat. Proc. Soc. exp. Biol. (N. Y.) 1957, 94, 223.

21. Abels, J., Woldring, M. G., Nieweg, H. O., Gaber, J. G., and de Vries, J. A. Ethylenediamine tetraacetate and the intestinal absorption of vitamin $B_{12}$. Nature (Lond.) 1959, 183, 1395.

22. Okuda, $K$. Vitamin $B_{12}$ absorption in rats studied by a "loop" technique. Amer. J. Physiol. 1960, 199, 84.

23. Herbert, V. Studies on the role of intrinsic factor and vitamin $\mathrm{B}_{12}$ absorption, transport, and storage. Amer. J. clin. Nutr. 1959, 7, 433. 